\title{
SiC/GaN Power Semiconductor Devices Theoretical Comparison and Experimental Evaluation
}

\author{
Ke Li, Paul Evans, Mark Johnson \\ Power Electronics, Machine and Control group \\ University of Nottingham, UK \\ Email:ke.li@nottingham.ac.uk, paul.evans@nottingham.ac.uk, mark.johnson@nottingham.ac.uk
}

\begin{abstract}
SiC}$ and $\mathrm{GaN}$ power transistors conduction loss and switching losses are compared in this paper. In order to compare performance of the same power rating device, a theoretical analysis is given to compare $\mathrm{SiC}$ device conduction loss and switching losses change when device maximal blocking voltage reduces by half. Then static and dynamic characteristics of commercial $\mathrm{SiC}$ and $\mathrm{GaN}$ power transistors are compared and it is shown that GaN-HEMT would still have smaller ON-state resistance and inter-electrode capacitance in comparison with a $600 \mathrm{~V} \mathrm{SiC}$ device. After that, switching losses $E_{\mathrm{sw}}$ of a GaNHEMT is measured and compared with that of a $1200 \mathrm{~V} \mathrm{SiC}$ JFET and a 600V SiC-MOSFET, in which it is shown that $E_{\mathrm{sw}}$ of a GaN-HEMT is smaller than a $\mathrm{SiC}$ power transistor with the same power rating.

Keywords-Wide bandgap power semiconductor device; GaNHEMT; SiC-JFET; SiC-MOSFET; Conduction loss; Switching loss
\end{abstract}

\section{INTRODUCTION}

Power electronics systems are largely used in electrical vehicles for electrical energy conversion [1], where power semiconductor devices play an important role. Understanding the characteristics of power semiconductor devices could help engineers design high efficiency, high power density power converters so as to improve overall performance of electrical vehicles such as increase range and reliability.

Wide bandgap power semiconductor devices like silicon carbide $(\mathrm{SiC})$ and gallium nitride $(\mathrm{GaN})$ are becoming one research hot topic recently, because they could operate in higher temperature, higher frequency and realize higher energy conversion efficiency in comparison with traditional silicon (Si) power semiconductor devices. Commercial SiC transistors (JFET, MOSFET) are able to withstand blocking voltage above $1200 \mathrm{~V}$, while commercial GaN transistor (HEMT) can block a maximal voltage of $650 \mathrm{~V}$. Current rating of the above devices can be found from a few amperes to a few tens of amperes. Both of the $\mathrm{SiC}$ and $\mathrm{GaN}$ devices can be applied in electrical vehicle based battery charger or power converters. Power semiconductor devices produce losses when they convert energy, so how to compare $\mathrm{SiC}$ and $\mathrm{GaN}$ power devices characteristics such as conduction loss and switching losses would be helpful for engineers when designing power electronics systems using in electrical vehicles.

Experimental comparison between $\mathrm{SiC}$ and $\mathrm{Si}$ power semiconductor devices [2] or between $\mathrm{GaN}$ and $\mathrm{Si}$ power semiconductor devices [3] can be found in literature. However, there are few publications about experimental comparison between $\mathrm{SiC}$ and $\mathrm{GaN}$ power semiconductor devices. One major reason is that voltage ratings of most commercial $\mathrm{SiC}$ and $\mathrm{GaN}$ devices do not match. The objective of this paper is at first to theoretically analyze how losses of $\mathrm{SiC}$ power devices change when blocking voltage reduces from $1200 \mathrm{~V}$ to $600 \mathrm{~V}$ and then experimentally compare switching losses of a commercial SiC-JFET, SiC-MOSFET and GaN-HEMT in different switching conditions.

The paper is structured with following sections: at first, theoretical comparison of conduction loss and switching losses of $\mathrm{SiC}$ power devices when reducing blocking voltage is analyzed. Then, commercial $\mathrm{SiC}, \mathrm{GaN}$ power devices characteristics of their datasheet values are compared. Meanwhile, measurement methods are presented on how to experimentally measure those characteristics. After that, device switching energy of a SiC-JFET, a SiC-MOSFET and a GaN-HEMT is measured based on switching circuit of each. Conclusions are given at last.

\section{THEORETICAL COMPARISON}

\section{A. Conduction loss comparison}

The structure of a MOSFET is shown in Fig. 1a, where it is shown that device ON-state resistance $R_{\mathrm{ON}}$ is mainly constituted by device channel resistance $R_{\mathrm{ch}}$ and drift region resistance $R_{\text {drift }}$.

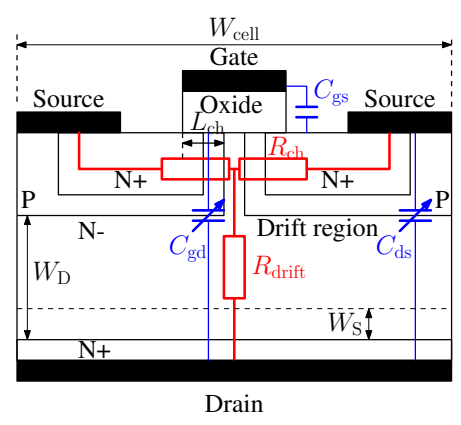

(a) MOSFET structure

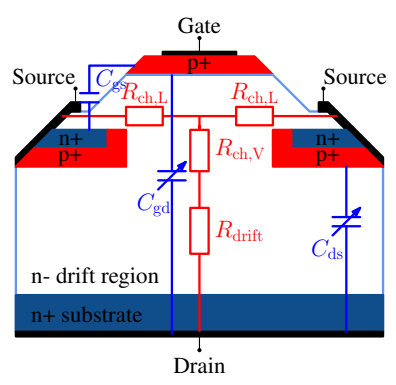

(b) JFET structure
Fig. 1: Structure of different power transistors

Multiplying by device active area $A$, the relation of each specific resistance $\left(m \Omega \cdot \mathrm{mm}^{2}\right)$ is expressed by the following equation: 


$$
R_{\mathrm{ON}, \mathrm{sp}}=R_{\mathrm{ch}, \mathrm{sp}}+R_{\mathrm{drift}, \mathrm{sp}}
$$

where device specific drift region resistance $R_{\text {drift,sp }}$ can be expressed by a function of device maximal blocking voltage $V_{\mathrm{DSS}}$, material permittivity $\epsilon$, carrier mobility in the drift region $\mu$ and critical electrical field $E_{\mathrm{c}}$ as given in [4]:

$$
R_{\mathrm{drift}, \mathrm{sp}}=\frac{4 V_{\mathrm{DSS}^{2}}}{\epsilon \mu E_{\mathrm{c}}{ }^{2}}
$$

Shown in [4], the minimal $R_{\text {drift,sp }}$ is a function of $V_{\mathrm{DSS}}{ }^{2.5}$, which means that for a $600 \mathrm{~V}$ device, its $R_{\text {drift,sp }}$ value could decrease to a factor of 5.6 in comparison with a $1200 \mathrm{~V}$ device. Device $R_{\mathrm{drift}, \mathrm{sp}}$ is also proportional to device drift region thickness $W_{\mathrm{D}}$. Thus, device $W_{\mathrm{D}}$ would decrease for a maximal factor of 5.6 for a $600 \mathrm{~V}$ device than a $1200 \mathrm{~V}$ device.

Device specific channel resistance $R_{\mathrm{ch}, \mathrm{sp}}$ can be approximately expressed by a function of device channel length $L_{\mathrm{ch}}$, unit cell width $W_{\text {cell }}$, channel mobility $\mu_{\mathrm{ch}}$ and accumulated charge in the channel $Q_{\mathrm{ch}}$ as shown in [5]:

$$
R_{\mathrm{ch}, \mathrm{sp}}=\frac{L_{\mathrm{ch}} \cdot W_{\mathrm{cell}}}{\mu_{\mathrm{ch}} \cdot Q_{\mathrm{ch}}}
$$

According to the results presented by authors in [6], $R_{\mathrm{ch}, \mathrm{sp}}$ varies little on $V_{\mathrm{DSS}}$ voltage.

By applying the parameters given by authors in [7] for a SiC-MOSFET, $R_{\mathrm{ch}, \mathrm{sp}}$ is found to be about $40 \%$ of the total $R_{\mathrm{ON}, \mathrm{sp}}$ of a $1200 \mathrm{~V}$ device. Thus, by combining the above equations, $R_{\mathrm{ON}, \mathrm{sp}}$ of a $600 \mathrm{~V}$ device decreases to half of the value of a $1200 \mathrm{~V}$ device.

The structure of one type of a commercial SiC-JFET (from Infineon) is shown in Fig. 1b, where device structure is quite similar to that of the MOSFET. For this device, $R_{\mathrm{ON}, \mathrm{sp}}$ equals to the sum of the specific lateral channel resistance $R_{\mathrm{ch}, \mathrm{L}}$, the specific vertical channel resistance $R_{\mathrm{ch}, \mathrm{V}}$ and the $R_{\mathrm{drift}, \mathrm{sp}}$. By applying parameters givens by authors in [8], it is found that $R_{\mathrm{ch}, \mathrm{sp}}$ is about half of the $R_{\mathrm{ON} \text {,sp }}$ value. Thus, for this type of SiC-JFET $R_{\mathrm{ON}, \mathrm{sp}}$ of a $600 \mathrm{~V}$ device is about $60 \%$ of the value of a $1200 \mathrm{~V}$ device. For another type of SiC-JFET where there is no lateral channel, by using the given doping concentration and thickness of both the drift region and device vertical channel in [9], it is found that $R_{\mathrm{ON}, \mathrm{sp}}$ of a $600 \mathrm{~V}$ device could decrease by a factor of 2 than that of a $1200 \mathrm{~V}$ device.

It can be summarized that according to the above analysis and calculation, $R_{\mathrm{ON}, \mathrm{sp}}$ of a $600 \mathrm{~V} \mathrm{SiC}$ device could decrease by a factor of 2 than a $1200 \mathrm{~V} \mathrm{SiC}$ device.

\section{B. Switching loss comparison}

It is illustrated in Fig. 1 the inter-electrode capacitances $C_{\mathrm{gd}}, C_{\mathrm{ds}}$ and $C_{\mathrm{gs}}$ between each terminal. Different like $C_{\mathrm{gs}}$, $C_{\mathrm{gd}}$ and $C_{\mathrm{ds}}$ are $V_{\mathrm{DS}}$ voltage dependent capacitances and their values can be approximately calculated by the following equation:

$$
C_{\mathrm{x}}=\frac{\epsilon \cdot A_{\mathrm{x}}}{W_{\mathrm{S}}}
$$
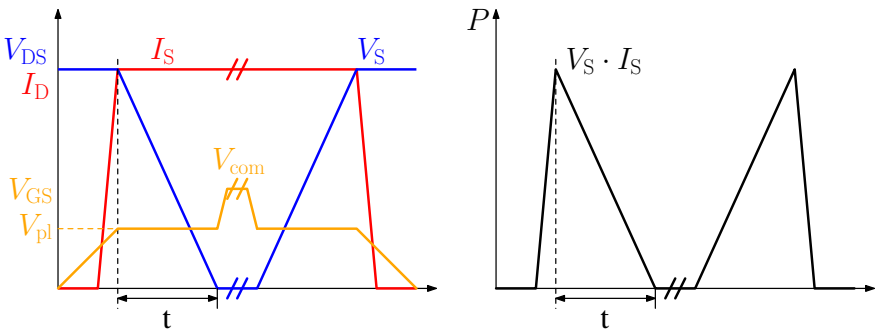

Fig. 2: Ideal switching waveforms and switching losses calculation

where $C_{\mathrm{x}}$ refers to either $C_{\mathrm{gd}}$ or $C_{\mathrm{ds}}, A_{\mathrm{x}}$ refers to the active area of each capacitance and $W_{\mathrm{S}}$ is depletion region thickness, which is dependent on device switching voltage $V_{\mathrm{S}}$.

Active area of $C_{\mathrm{gd}}$ and $C_{\mathrm{ds}}$ is obtained by multiplying a coefficient $b$ to the device area $A$. The relation between $W_{\mathrm{D}}$ and $W_{\mathrm{S}}$ is obtained by the following equation given in [4]:

$$
W_{\mathrm{S}}=W_{\mathrm{D}} \cdot \sqrt{\frac{V_{\mathrm{S}}}{V_{\mathrm{DSS}}}}
$$

By combining eq.(4) and eq.(5), stored charge $Q_{\mathrm{x}}$ of each capacitor during switching can be obtained by:

$$
\begin{aligned}
\int_{0}^{Q_{\mathrm{x}}} \mathrm{d}_{q_{\mathrm{x}}} & =\int_{0}^{V_{\mathrm{S}}} C_{\mathrm{x}} \mathrm{d}_{v_{\mathrm{S}}} \\
Q_{\mathrm{x}} & =\frac{2 b \cdot \epsilon \cdot A}{W_{\mathrm{D}}} \cdot \sqrt{V_{\mathrm{DSS}}} \cdot \sqrt{V_{\mathrm{S}}}
\end{aligned}
$$

Thus, the comparison of specific charge $\left(Q_{\mathrm{x}, \mathrm{sp}}\right)$ between $600 \mathrm{~V}$ and $1200 \mathrm{~V}$ device can be obtained by following equation, which is shown that $Q_{\mathrm{x}, 600 \mathrm{~V}}$ is bigger than $Q_{\mathrm{x}, 1200 \mathrm{~V}}$.

$$
\frac{Q_{\mathrm{x}, 600 \mathrm{~V}}}{Q_{\mathrm{x}, 1200 \mathrm{~V}}}=0.7 \cdot \frac{W_{\mathrm{D}, 1200 \mathrm{~V}}}{W_{\mathrm{D}, 600 \mathrm{~V}}}
$$

Power transistor ideal switching waveforms (device switching at voltage $V_{\mathrm{S}}$ and current $I_{\mathrm{S}}$ ) is shown in Fig. 2, where transistor gate-drain charge $Q_{\mathrm{gd}}$ plays an important role in device switching, because its discharge and charge time $t$ by gate current $I_{\mathrm{g}}$ influence on device switching losses. Thus, device switching losses $E_{\mathrm{sw}}$ of one period can be approximately calculated by the following equation:

$$
E_{\mathrm{sw}}=V_{\mathrm{S}} \cdot I_{\mathrm{S}} \cdot t=V_{\mathrm{S}} \cdot I_{\mathrm{S}} \cdot \frac{Q_{\mathrm{gd}}}{I_{\mathrm{g}}}=V_{\mathrm{S}} \cdot I_{\mathrm{S}} \cdot \frac{Q_{\mathrm{gd}}}{V_{\mathrm{com}}-V_{\mathrm{pl}}} \cdot R_{\mathrm{g}}
$$

where $R_{\mathrm{g}}$ is gate resistor, $V_{\text {com }}$ is controlled gate voltage and $V_{\mathrm{pl}}$ is Miller-plate voltage. It is to be noted that device output capacitance $C_{\text {oss }}$ stored energy $E_{\text {oss }}$ would be dissipated during turn-ON switching and $E_{\text {oss }}$ would be recovered during turn-OFF switching. By adding $E_{\text {oss }}$ in turn-ON switching and subtracting it from turn-OFF switching, eq.(8) can be still used to estimate device total switching loss.

It is shown in this equation that $E_{\mathrm{sw}}$ is proportional to $Q_{\mathrm{gd}}$, thus it is proportional to the term $\sqrt{V_{\mathrm{DSS}}} \cdot \frac{A}{W_{\mathrm{D}}}$. In contrary 
to the comparison result of $R_{\mathrm{ON}, \mathrm{sp}}$, it is found that device specific switching loss $E_{\mathrm{sw}, \mathrm{sp}}$ of $600 \mathrm{~V}$ is bigger than $1200 \mathrm{~V}$ device, because device specific capacitance of $600 \mathrm{~V}$ device is bigger than $1200 \mathrm{~V}$ device.

\section{C. $600 \mathrm{~V} / 1200 \mathrm{~V}$ device comparison}

Device maximal conduction current $I_{\mathrm{D}}$ is limited by its heat dissipation, which is calculated by the following equation:

$$
I_{\mathrm{D}}^{2} \cdot R_{\mathrm{ON}} \cdot R_{\mathrm{th}}=T_{\mathrm{j}(\max )}
$$

Only device thermal resistance $R_{\mathrm{th}}$ of die is considered (without influence of packaging), which is determined by device length (which is supposed to be device drift region thickness $W_{\mathrm{D}}$ for a transistor), active area $A$ and material thermal conductivity $k$. Thus,

$$
R_{\mathrm{th}}=\frac{W_{\mathrm{D}}}{k \cdot A}
$$

By combining eq.(9) and eq.(10), following equation can be obtained:

$$
I_{\mathrm{D}}=\sqrt{T_{\mathrm{j}(\max )} \cdot k} \cdot \frac{A}{\sqrt{R_{\mathrm{ON}, \mathrm{sp}}} \cdot \sqrt{W_{\mathrm{D}}}}
$$

As shown in section II-A, $R_{\mathrm{ON}, \mathrm{sp}}$ reduces half when $V_{\mathrm{DSS}}$ decreases to a half. Thus, for a $600 \mathrm{~V}$ device of the same current rating, $\frac{A}{\sqrt{W_{\mathrm{D}}}}$ should decrease to a factor of 1.4 of a 1200V device.

By combing with above $E_{\mathrm{sw}}$ analysis, following equation can be obtained in terms of the $E_{\mathrm{sw}}$ comparison between $1200 \mathrm{~V}$ device and $600 \mathrm{~V}$ device, which shows that $E_{\mathrm{sw}}$ is inversely proportional to the square root of device drift region thickness. According to eq.(12), switching loss of a $600 \mathrm{~V}$ device might be superior to a $1200 \mathrm{~V}$ with the same current rating.

$$
\frac{E_{\mathrm{sw}, 1200 \mathrm{~V}}}{E_{\mathrm{sw}, 600 \mathrm{~V}}}=2 \cdot \sqrt{\frac{W_{\mathrm{D}, 600 \mathrm{~V}}}{W_{\mathrm{D}, 1200 \mathrm{~V}}}}
$$

$\mathrm{SiC}$ and $\mathrm{GaN}$ power devices will be experimentally compared in the next section in order to evaluate their performance.

\section{EXPERIMENTAL VALIDATION}

\section{A. Device characteristics comparison and measurement}

Device $R_{\mathrm{ON}}$ datasheet values of a SiC-JFET (IJW120R100T1，1200V/26A, $V_{\mathrm{th}} \approx-13.5 \mathrm{~V}$ ), a $1200 \mathrm{~V}$ SiC-MOSFET (CMF10120D, 1200V/24A, $\left.V_{\text {th }} \approx 2.5 \mathrm{~V}\right)$, a $\left.650 \mathrm{~V} \mathrm{SiC-MOSFET} \mathrm{(SCT2120AF,} \mathrm{650V/29A,} V_{\mathrm{th}} \approx 2.8 \mathrm{~V}\right)$ and a GaN-HEMT (GS66508P, 650V/30A, $\left.V_{\text {th }} \approx 1.4 \mathrm{~V}\right)$ are compared in Fig. 3, which shows that for a power device with the same current rating, $R_{\mathrm{ON}}$ of GaN-HEMT is about half of that of $\mathrm{SiC}$ device. $R_{\mathrm{ON}}$ of $650 \mathrm{~V} \mathrm{SiC-MOSFET}$ is about $75 \%$ of $1200 \mathrm{~V}$ device, which confirms the theoretical study that in comparison with a $1200 \mathrm{~V} \mathrm{SiC} \mathrm{device} \mathrm{with} \mathrm{the} \mathrm{same} \mathrm{current}$ rating, $R_{\mathrm{ON}}$ of a $600 \mathrm{~V} \mathrm{SiC}$ would decrease by a factor of $2 \rho\left(\rho=\frac{A_{(600 \mathrm{~V})}}{A_{(1200 \mathrm{~V})}}<1\right)$, which might be still superior to $\mathrm{GaN}$

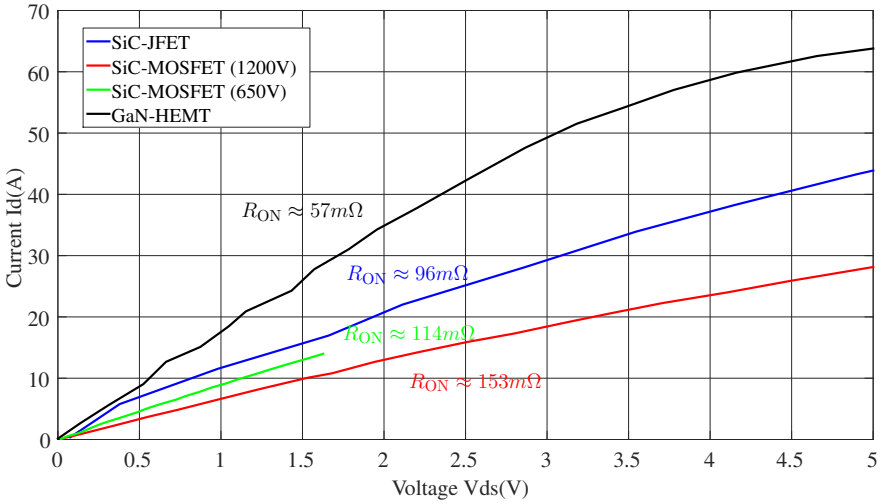

Fig. 3: Device $R_{\mathrm{ON}}$ comparison at $25^{\circ} \mathrm{C}$

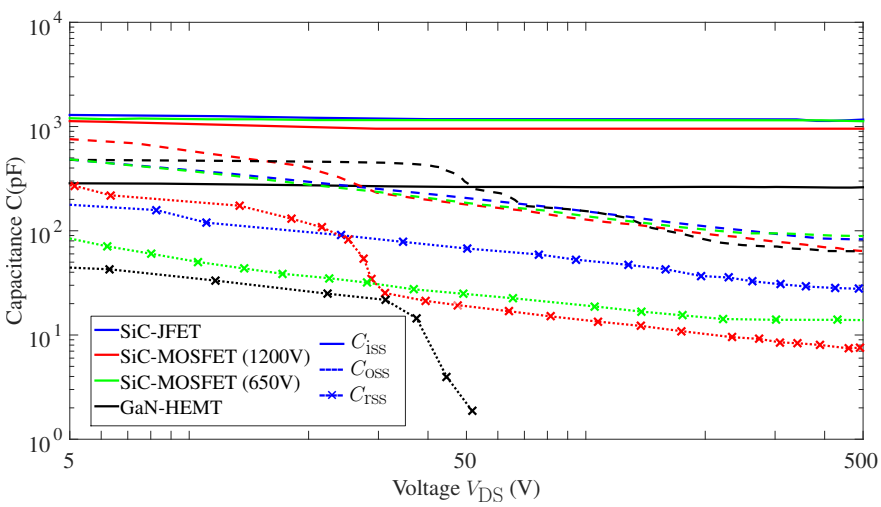

Fig. 4: Device inter-electrode capacitance comparison

device. Device datasheet of another 600V/40A SiC-MOSFET [10] (GP1T072A060B, 600V/40A, $V_{\text {th }} \approx 2.8 \mathrm{~V}$ ) show that its $R_{\mathrm{ON}}$ is about $72 \mathrm{~m} \Omega$, which is still bigger than $\mathrm{GaN}$ device.

Device $R_{\mathrm{ON}}$ values can be experimentally measured in a curve tracer or in any electrical circuit where device conduction current and voltage drop are measured.

Datasheet values of the inter-electrode capacitance comparison of the above devices is shown in Fig. 4, where device input capacitance $C_{\text {iss }}=C_{\mathrm{gs}}+C_{\mathrm{gd}}$, output capacitance $C_{\mathrm{oss}}=C_{\mathrm{ds}}+C_{\mathrm{gd}}$ values of SiC-JFET and SiC-MOSFET are similar. Reverse transfer capacitance $C_{\mathrm{rss}}=C_{\mathrm{gd}}$ of $\mathrm{GaN}$ HEMT is much smaller than that of SiC-JFET and SiCMOSFET, which demonstrates a faster transition than $\mathrm{SiC}$ devices. Shown in Fig. 4, $Q_{\mathrm{gd}}$ of GaN-HEMT is about 5 times smaller than that of SiC-MOSFET and 10 times smaller than that of SiC-JFET if device switches from 300V.

It is also presented in Fig. 4 that $600 \mathrm{~V}$ inter-electrode capacitances are bigger than $1200 \mathrm{~V}$ device in some $V_{\mathrm{DS}}$ voltage range, which confirms the above theoretical analysis. If one compares the datasheet of the above $600 \mathrm{~V} / 40 \mathrm{~A}$ SiC-MOSFET with a 1200V/32A SiC-MOSFET [11] (GP1T080A120B, $V_{\mathrm{th}} \approx 2.8 \mathrm{~V}$ ) of another manufacturer, it can be noted that inter-electrode capacitances of the former device are also bigger than the latter one. 


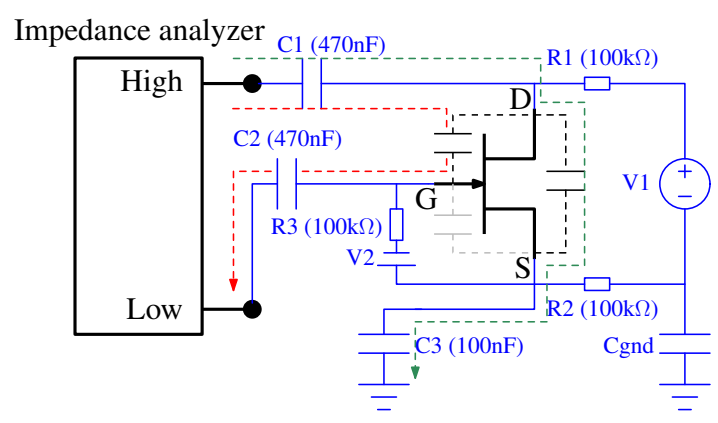

Fig. 5: Power transistor $C_{\mathrm{gd}}$ measurement by an impedance analyzer with ground connection

The inter-electrode capacitances values of the GaN-HEMT in Fig. 4 are given on a linear-linear scale in the device datasheet. Thus, it is difficult to extract $C_{\text {rss }}$ value due to the strong non-linearity of its value. Power semiconductor device inter-electrode capacitances can be measured by small signal method, where device is biased by external DC voltage and small signal can be either generated by an impedance analyzer [12] or by a vector network analyzer [13].

One solution to measure device inter-electrode capacitance is shown in Fig. 5, where an impedance analyzer (IA) and ground connection is used. Device $V_{\mathrm{DS}}$ and $V_{\mathrm{GS}}$ are biased by external voltage sources. Three external capacitors are used to block the DC voltage between device terminals with IA connector and ground, while their impedance is neglected when passing high frequency ( $\mathrm{MHz}$ range) $\mathrm{AC}$ current. High impedance branches are constituted by three big resistances, which guarantees that all the AC current flow though the transistor. In the electrical circuit shown in Fig. 5, only current flowing through $C_{\mathrm{gd}}$ is measured by IA, because current flowing through capacitance $C_{\mathrm{ds}}$ flows to the ground. By varying $V_{\mathrm{DS}}$ voltage, device $C_{\mathrm{gd}}$ values of different biased voltages are measured. Other measurement circuits can be used to measure $C_{\mathrm{gs}}$ and $C_{\mathrm{ds}}$ capacitance with similar measurement principle.

By knowing device inter-electrode capacitances, device switching losses can be measured and results will be presented in the next subsection.

\section{B. Device switching losses measurement}

The switching energy $E_{\mathrm{sw}}$ of above $1200 \mathrm{~V} / 26 \mathrm{~A}$ SiC-JFET, 650V/29A SiC-MOSFET and 650V/30A GaN-HEMT are compared.

The electrical circuit of the switching mesh is shown in Fig. 6a, in which it is constituted by a bus capacitor $C_{\text {bus }}$, a half bridge circuit with two power semiconductor devices S1 and S2 together with their drivers. Lower device drain switching current $I_{\mathrm{D}}$ and drain source switching voltage $V_{\mathrm{DS}}$ are measured to calculate the device switching energy.

For the SiC-MOSFET, the realization circuit is shown in Fig. $6 \mathrm{~b}$, in which the device is in TO-220 package. The device is switched with a gate voltage from $-5 \mathrm{~V}$ to $20 \mathrm{~V}$ and the external gate resistance is $0 \Omega$. A hall-effect current

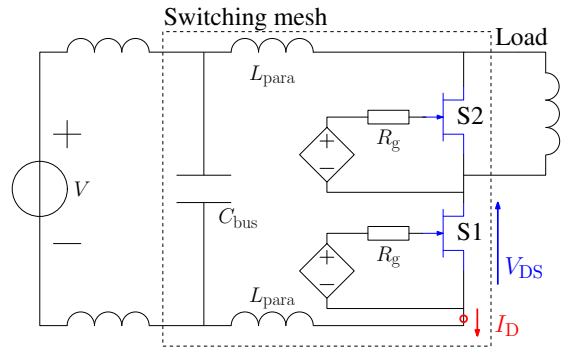

(a) Electrical circuit of the switching circuit

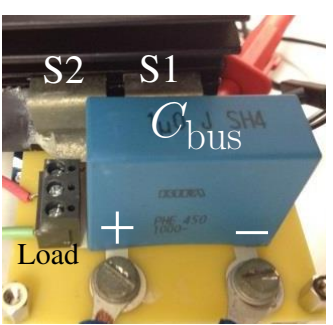

(b) Switching circuit of SiCMOSFET

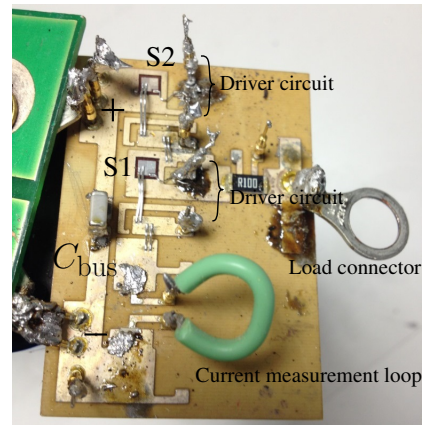

(c) Switching circuit of SiC-JFET

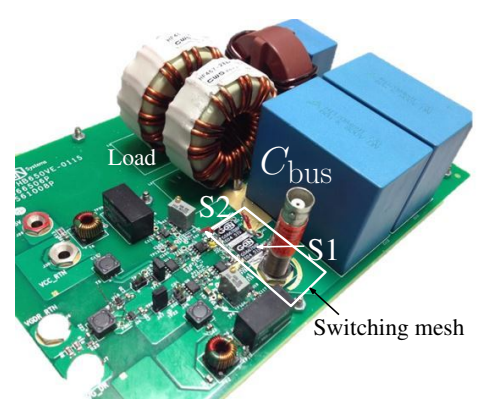

(d) Switching circuit of GaN-HEMT
Fig. 6: Electrical circuit of the switching circuit and their realization

probe $(\mathrm{TCP} 312,100 \mathrm{MHz})$ is used to measure $I_{\mathrm{D}}$ and an active differential voltage probe (TA043, $100 \mathrm{MHz}$ ) is used to measure $V_{\mathrm{DS}}$.

For the SiC-JFET, the realization circuit is shown in Fig. 6c, in which the die of the device is mounted in a copper substrate. The device is switched with a gate voltage from $-18 \mathrm{~V}$ to $0 \mathrm{~V}$ and the external gate resistance is $0 \Omega$. An AC current probe (P6022, 1kHz-120MHz) is used to measure $I_{\mathrm{D}}$ and the same active differential voltage probe is used to measure $V_{\mathrm{DS}}$.

For the GaN-HEMT, the realization circuit is shown in Fig. 6d. The device is switched with a gate voltage from $0 \mathrm{~V}$ to $7 \mathrm{~V}$ and the gate resistance is $20 \Omega$ for device turn-ON switching. A current shunt (SSDN-10, $0.1 \Omega, 2 \mathrm{GHz}$ ) is used to measure $I_{\mathrm{D}}$ and a high voltage passive voltage probe (PPE4kV, $400 \mathrm{MHz}$ ) is used to measure $V_{\mathrm{DS}}$. Switching mesh is kept as small as possible in all designs so as to minimize parasitic inductance $L_{\text {para }}$ in the switching loop.

All devices are tested in double-pulse test in order to keep device junction temperature constant at $25^{\circ} \mathrm{C}$. The switching waveforms comparison when devices switch at $V_{\mathrm{DS}}=200 \mathrm{~V}$ and $I_{\mathrm{D}}=5 \mathrm{~A}$ is shown in Fig. 7 while the results when devices switch at $V_{\mathrm{DS}}=300 \mathrm{~V}$ and $I_{\mathrm{D}}=10 \mathrm{~A}$ is shown in Fig. 8. It is shown in the results that GaN-HEMT switches faster than both SiC-JFET and SiC-MOSFET in those switching conditions, which give rise to a higher $d \mathrm{i} / d \mathrm{t}$ and $d \mathrm{v} / d \mathrm{t}$. Device $E_{\mathrm{sw}}$ can be calculated based on the measured switching waveforms and they are compared in Fig. 9 of different switching conditions.

As shown in the results, when device switches at $200 \mathrm{~V}$, $E_{\mathrm{sw}}$ of GaN-HEMT is about $1 / 3$ smaller than that of SiC- 

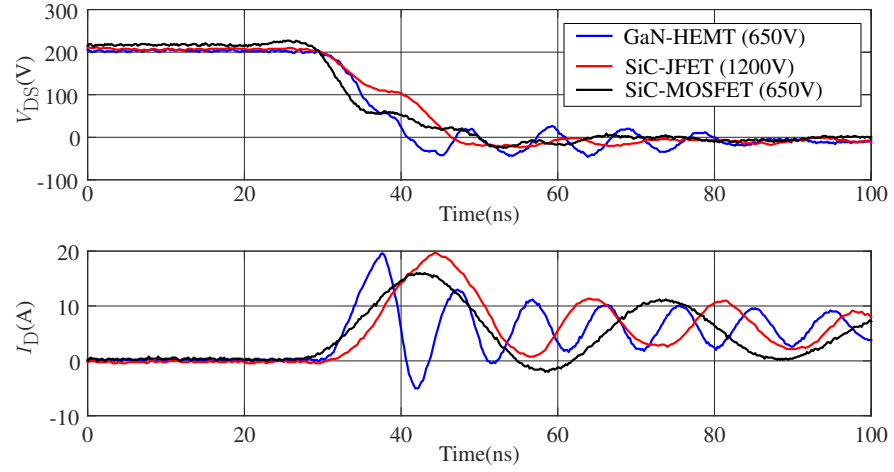

(a) Device ON
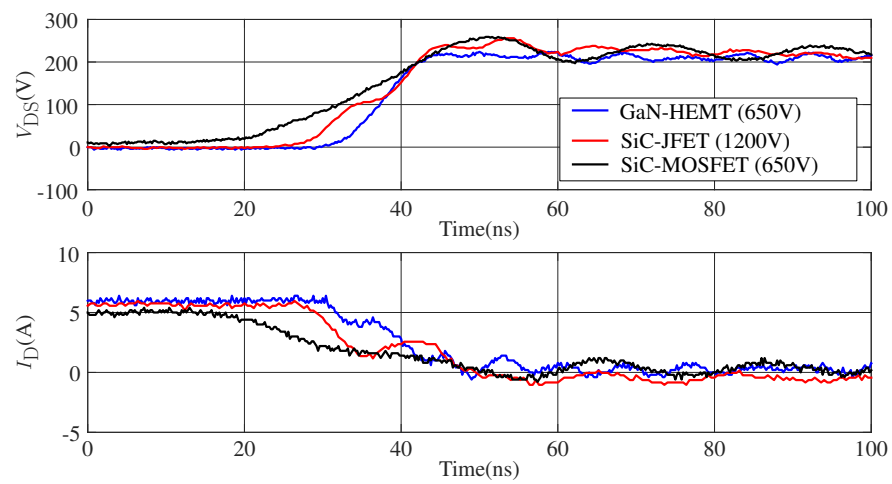

(b) Device OFF

Fig. 7: Switching waveforms comparison when device switches at $V_{\mathrm{DS}}=200 \mathrm{~V}$ and $I_{\mathrm{D}}=5 \mathrm{~A}$

JFET and about half of SiC-MOSFET; while when device switches at $300 \mathrm{~V}, E_{\mathrm{sw}}$ of GaN-HEMT is about $40 \%$ smaller than that of SiC-JFET and about half of SiC-MOSFET. It is to be noted that as device package of the above devices is not the same, device internal gate resistance and switching loop inductance are not the same, which might slightly influence on obtained $E_{\mathrm{sw}}$ values based on the results presented by authors in [14]. However, according to eq.(8) and in eq.(12), $E_{\mathrm{sw}}$ of GaN-HEMT can be further decreased by using a smaller gate resistance.

In order to validate above theoretical analysis on device switching loss, switching waveforms of a $1200 \mathrm{~V} / 60 \mathrm{~A}$ SiC-MOSFET (C2M0040120D) is compared with the above $650 \mathrm{~V} / 30 \mathrm{~A}$ SiC-MOSFET. The comparison results when device switches at $300 \mathrm{~V}$ and $10 \mathrm{~A}$ are shown in Fig. 10, where it is shown that $1200 \mathrm{~V} / 60 \mathrm{~A}$ device switches faster than $650 \mathrm{~V} / 30 \mathrm{~A}$ device in terms of $d \mathrm{i} / d \mathrm{t}$ and $d \mathrm{v} / d \mathrm{t}$. It is to be noted that 1200V/60A MOSFET has bigger current conduction capability than 1200V/30A MOSFET, thus has bigger capacitance values as well. It suggests that even one compares the $E_{\mathrm{sw}}$ between $650 \mathrm{~V} / 30 \mathrm{~A}$ device and $1200 \mathrm{~V} / 30 \mathrm{~A}$ device with the same current rating, the former device has bigger $E_{\mathrm{sw}}$ than the latter one, which confirms the above analysis that $650 \mathrm{~V}$ $\mathrm{SiC}$ device might produce bigger switching losses than $1200 \mathrm{~V}$ device.

By combining all the above measurement results, it is shown
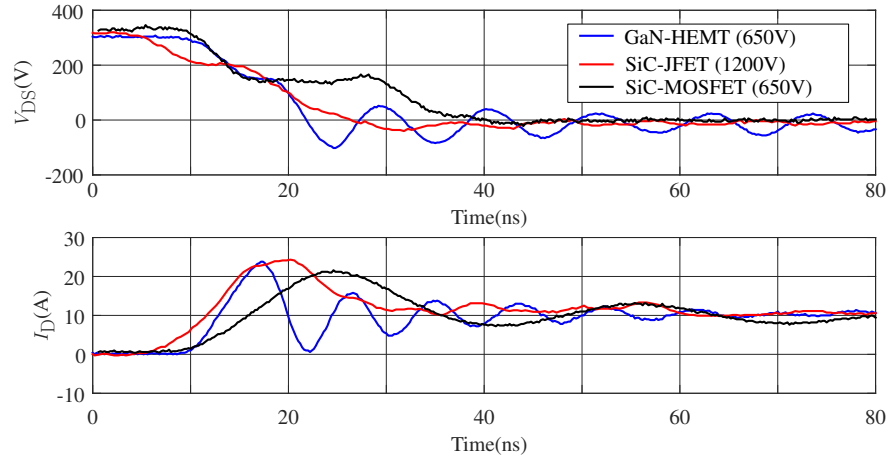

(a) Device ON
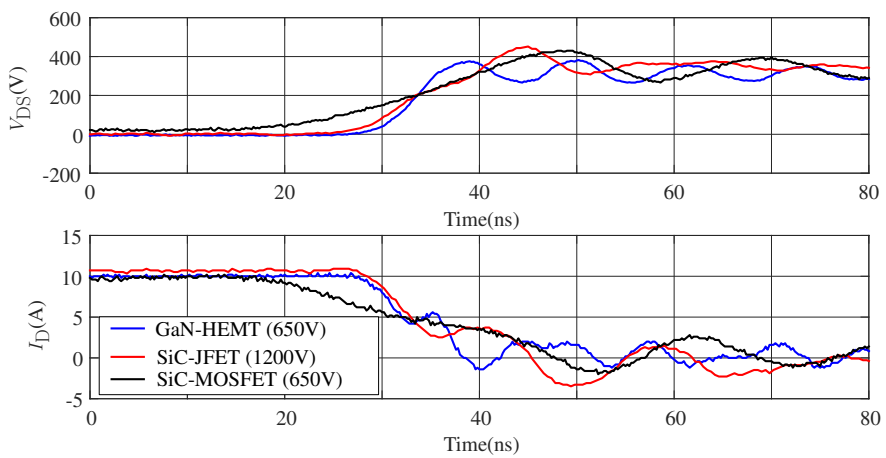

(b) Device OFF

Fig. 8: Switching waveforms comparison when device switches at $V_{\mathrm{DS}}=300 \mathrm{~V}$ and $I_{\mathrm{D}}=10 \mathrm{~A}$
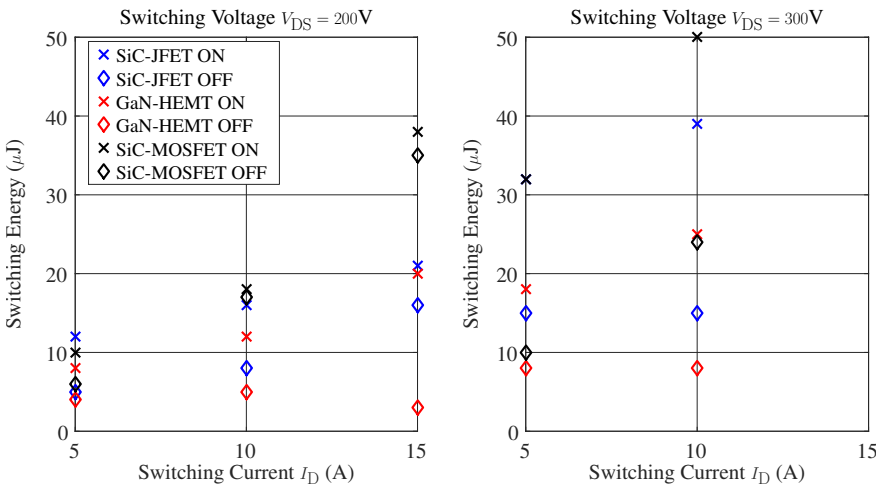

Fig. 9: Device switching energy comparison of different switching conditions

that $\mathrm{GaN}$ device produces less switching loss in comparison with a $600 \mathrm{~V}$ or $1200 \mathrm{~V} \mathrm{SiC}$ device with the same current rating and it is more suitable than $\mathrm{SiC}$ device to be applied in below $300 \mathrm{~V}$ energy conversion.

\section{CONCLUSION}

$\mathrm{SiC}$ and $\mathrm{GaN}$ power semiconductor devices conduction loss and switching losses are compared in the paper. In order to compare losses of devices with the same power rating, a theoretical analysis is given, where it is shown that specific $\mathrm{ON}$-state resistance of $\mathrm{SiC}$ power transistors will reduce half 

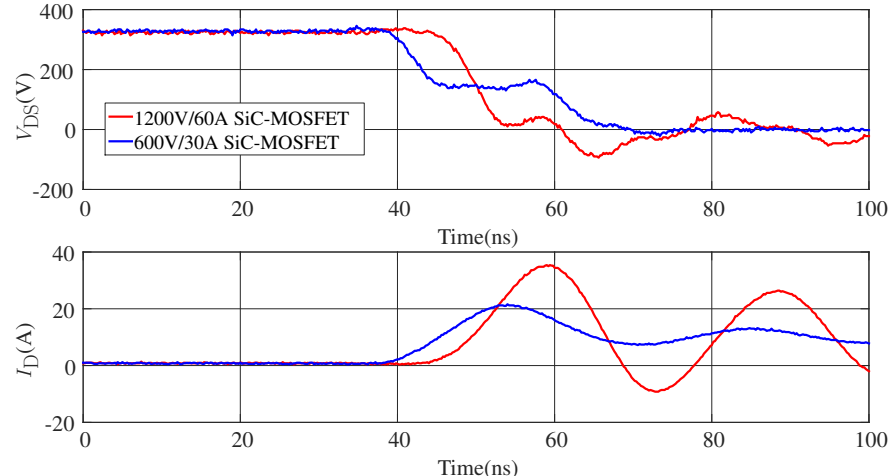

(a) Device ON
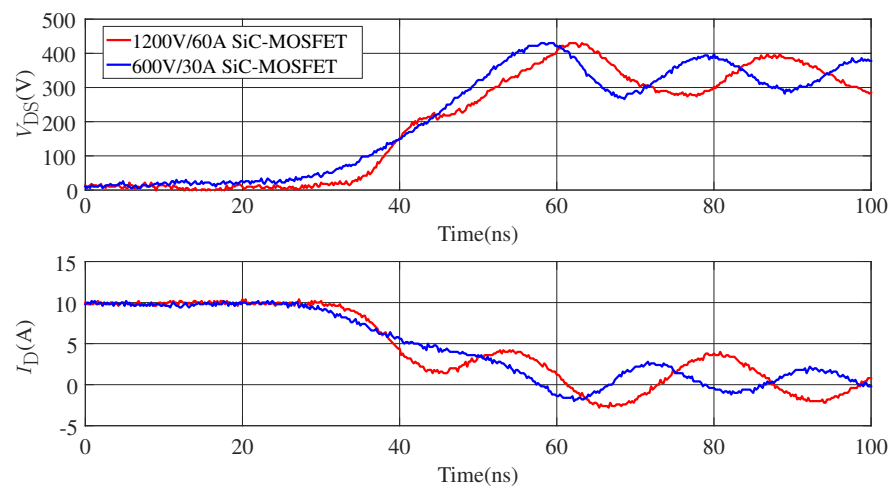

(b) Device OFF

Fig. 10: Switching waveforms comparison between $1200 \mathrm{~V}$ and $600 \mathrm{~V}$ SiC-MOSFET switching at $V_{\mathrm{DS}}=300 \mathrm{~V}$ and $I_{\mathrm{D}}=10 \mathrm{~A}$

if device maximal blocking voltage decreases half. In contrary to that, device specific capacitance value would increase. Thus, for device with same current rating, switching losses $E_{\mathrm{sw}}$ is inversely proportional to the square root of device drift region thickness, which illustrates that switching loss would increase in a $600 \mathrm{~V} \mathrm{SiC} \mathrm{device.}$

Static and dynamic characteristics of $1200 \mathrm{~V}$ and $600 \mathrm{~V} \mathrm{SiC}$ power transistors are compared with $600 \mathrm{~V}$ GaN-HEMT, in which it is found that GaN-HEMT has a half smaller $R_{\mathrm{ON}}$ and about at least five times smaller gate drain capacitance charge $Q_{\mathrm{gd}}$. Inter-electrode capacitances values of a $600 \mathrm{~V}$ SiC-MOSFET is even bigger than a $1200 \mathrm{~V}$ device in some voltage range, which helps to validate the presented theoretical analysis.

By comparing $E_{\mathrm{sw}}$ in the switching test, it is found that GaN-HEMT produce from a third to $40 \%$ less switching loss than $1200 \mathrm{~V}$ SiC-JFET and only a half $E_{\mathrm{sw}}$ as $600 \mathrm{~V} \mathrm{SiC}$ MOSFET in different switching conditions. It is also shown in the results that $1200 \mathrm{~V} \mathrm{SiC-MOSFET} \mathrm{switches} \mathrm{faster} \mathrm{than}$ $600 \mathrm{~V}$ device, which confirms the theoretical analysis of device switching losses. By using a smaller gate resistor, $E_{\mathrm{sw}}$ of $\mathrm{GaN}$ HEMT will be further decreased, and it is more suitable than $\mathrm{SiC}$ device to be applied in below $300 \mathrm{~V}$ energy conversion.

\section{ACKNOWLEDGMENT}

The authors would like to thank UK Engineering and Physical Sciences Research Council (EPSRC) for the financial support under EP/K014471/1 and all the partners of the project Silicon Compatible GaN Power Electronics for technical discussions.

\section{REFERENCES}

[1] J. Wang, "Practical design considerations of power electronics in hybrid and fuel cell vehicles," in 2008 IEEE Vehicle Power and Propulsion Conference, pp. 1-6, Sept 2008.

[2] M. Chinthavali, P. Otaduy, and B. Ozpineci, "Comparison of Si and $\mathrm{SiC}$ inverters for IPM traction drive," in 2010 IEEE Energy Conversion Congress and Exposition, pp. 3360-3365, Sept 2010.

[3] M. Acanski, J. Popovic-Gerber, and J. A. Ferreira, "Comparison of Si and GaN power devices used in PV module integrated converters," in 2011 IEEE Energy Conversion Congress and Exposition, pp. 1217-1223, Sept 2011.

[4] J. Lutz, H. Schlangenotto, U. Scheuermann, and R. De Doncker, Semiconductor Power Devices. Springer, 2011.

[5] B. Baliga, Advanced High Voltage Power Device Concepts. Springer, 2011.

[6] D. Ueda, H. Takagi, and G. Kano, "A new vertical power MOSFET structure with extremely reduced on-resistance," IEEE Transactions on Electron Devices, vol. 32, pp. 2-6, Jan 1985.

[7] M. Ruff, H. Mitlehner, and R. Helbig, "SiC devices: physics and numerical simulation," IEEE Transactions on Electron Devices, vol. 41, pp. 1040-1054, Jun 1994.

[8] R. Mousa, Caractrisation, modlisation et intgration de JFET de puissance en carbure de silicium dans des convertisseurs haute temprature et haute tension. PhD thesis, L'INSA de Lyon, 2009.

[9] P. Friedrichs, H. Mitlehner, K.-O. Dohnke, and D. Peters et al., "SiC power devices with low on-resistance for fast switching applications," in Power Semiconductor Devices and ICs, 2000. Proceedings. The 12th International Symposium on, pp. 213-216, 2000.

[10] Global Power Technologies Group, GP1T072A060B datasheet, 2016.

[11] Globa 1Power Technologies Group, GP1T080A120B datasheet, 2016.

[12] Z. Chen, D. Boroyevich, R. Burgos, and F. Wang, "Characterization and modeling of $1.2 \mathrm{kV}, 20 \mathrm{~A} \mathrm{SiC} \mathrm{MOSFETs,"} \mathrm{in} \mathrm{Energy} \mathrm{Conversion}$ Congress and Exposition, 2009. ECCE 2009. IEEE, pp. 1480 -1487, sept. 2009.

[13] K. Li, A. Videt, and N. Idir, "Multiprobe Measurement Method for Voltage-Dependent Capacitances of Power Semiconductor Devices in High Voltage," Power Electronics, IEEE Transactions on, vol. 28, no. 11, pp. 5414-5422, 2013.

[14] J. Wang, H. S.-h. Chung, and R. T.-h. Li, "Characterization and Experimental Assessment of the Effects of Parasitic Elements on the MOSFET Switching Performance," Power Electronics, IEEE Transactions on, vol. 28 , pp. $573-590$, jan. 2013. 